\title{
ENTRE EU E O OUTRO: IDENTIFICAÇÕES E RESISTÊNCIAS DO(A) PROFESSOR(A)
}

\section{BETWEEN ME AND THE OTHER: IDENTIFICATIONS AND RESISTANCE OF THE TEACHER}

\author{
LIMA, Josciene de Jesus \\ joli.lima@gmail.com \\ USF - Universidade São Francisco \\ MASCIA, Márcia Aparecida Amador \\ marciaaam@uol.com.br \\ USF - Universidade São Francisco
}

\begin{abstract}
RESUMO Este artigo tem por objetivo compreender os modos de identificação do(a) professor(a) junto à profissão docente. O referencial teórico-metodológico baseia-se nos postulados da Análise de Discurso, nos estudos foucaultianos e nos estudos culturais, considerando: o discurso de natureza tridimensional - linguagem, história e ideologia na perspectiva discursiva; modos de identificação como resultados dos processos de objetivação e de subjetivação e identidade na perspectiva cultural. $O$ corpus consiste em excertos de entrevistas de três professoras. Os resultados indicam modos de identificação do(a) professor(a) com a profissão docente, principalmente, pelo aspecto negativo e por meio de resistência, na medida em que o(a) professor(a) dribla as adversidades, resiste e permanece na profissão docente.
\end{abstract}

PALAVRAS- CHAVE: Modos de identificação. Profissão docente. Resistência

ABSTRACT This paper has the aim of understanding the modes of identification of the teacher in relation to his/her profession. The methodological framework consists of the Discourse Analysis, foucaultian studies and cultural studies considering: the discourse in a tridimensional nature - language, history and ideology in the discursive perspective; modes of identification as results of the process of objectivation and subjectivation, and identity in cultural perspective. The corpus consists in excerpts of interviews of three teachers. The results of the analysis indicate that the modes of identification of the teacher in relation to his/her profession has been, mainly, by the negative aspects and resistance, in the way the teacher overcomes the adversities, he/she resists and stays in the teacher profession.

Keywords: Modes of identification. Teacher profession. Resistance.

\section{INTRODUÇÃO}




\section{Atos de Pesquisa em Educação - ISSN 1809-0354 \\ Blumenau - vol. 11, n. 2, p.492-508 ago./nov. 2016 \\ DOI: http://dx.doi.org/10.7867/1809-0354.2016v11n2p492-508}

Discutir modos de identificação do(a) professor(a) com a profissão docente requer repousar o olhar sobre objetivação e subjetivação do professor. Nesse sentido, convém analisar essa construção com base no contexto histórico e social, em que o(a) professor(a) projeta-se a partir da imagem social do 'eu', do 'eu com o Outro' e do 'eu com tantos outros'.

Nessa perspectiva, abrir uma discussão sobre essa temática implica transitar no meio em que se questiona uma possível "crise de identidade" do(a) professor(a), expressão comum em livros, em reportagens jornalísticas e até em conversas informais entre profissionais de educação e pela sociedade, de modo geral. É considerar as inúmeras associações que se faz do professor e da profissão docente, como um apelo para resgatar o prestígio e o status, perdidos ao longo dos anos.

Esse dizer torna-se contraditório no momento em que as iniciativas têm ficado aquém do essencial para reverter o quadro negativo e da presença de chavões que indicam concepções negativas sobre a profissão docente. É comum associar o(a) professor(a) a uma metáfora de luta, via expressões do tipo guerreiro, sofredor e lutador. Por outro lado, faz-se associação da profissão e do(a) professor(a) à pobreza extrema.

Destarte, entendemos que ser professor passa por diferentes zonas de conflitos e implica, principalmente, ser possuidor de poder, qualquer que seja o tipo de poder que se instaura na relação do professor consigo próprio e com o outro (colega de profissão, alunos, sociedade e profissão). Não se pode negar que a profissão docente ou o profissional docente enfrenta dilemas e desafios no contexto do novo cenário nacional/mundial, sendo produzidos novos sentidos e novos significados para o(a) professor(a), para/na sociedade.

Assim, inquieta-nos transitar no mundo das subjetividades reconhecendo-as como produtoras de identificações. Nesse sentido, o discurso se apresenta como corpus da materialidade linguística, na perspectiva foucaultiana do sujeito construído historicamente e isso implica pensarmos o sujeito como inacabado, em construção. Assim, um discurso sempre se remete a outro discurso, o que já foi dito é dito de outra forma. Nessa perspectiva, Grigoletto (2002, p. 37) argumenta que "o traço que define 


\section{Atos de Pesquisa em Educação - ISSN 1809-0354 \\ Blumenau - vol. 11, n. 2, p.492-508 ago./nov. 2016 \\ DOI: http://dx.doi.org/10.7867/1809-0354.2016v11n2p492-508}

a função sujeito é a ilusão constitutiva de ser a origem do que diz pelo mascaramento ideológico de que seu discurso sempre remete a um Outro".

Como objetivo da investigação procuramos compreender os modos de identificação dos(as) professores(as) junto à profissão docente. O corpus discursivo consta de entrevista semiestruturada com duas professoras da educação básica - 1ำ ao 9o ano - na Bahia/Brasil. Como desdobramento desse objetivo, procuramos identificar nas formações discursivas das professoras, as formas de resistência e sua relação com os modos de identificação; apontar como os modos de identificação das professoras se materializam linguisticamente.

A análise pauta-se na Análise do Discurso, considerando o discurso na natureza tridimensional - linguagem, história e ideologia (ORLANDI, 1996; PÊCHEUX, 1997) e que a escola se constitui em espaço de poder a partir das relações de luta e de força que envolve o professor, o Outro e os outros (FOUCAULT, 1979).

Percebemos identificação das professoras a partir dos aspectos positivos e dos aspectos negativos sobre os quais fizeram referência. A resistência se constitui em um modo de identificação, tomando-a como uma manifestação de poder, o(a) professor(a) resiste aos impactos negativos e permanece na profissão docente.

Neste trabalho, em especial na análise, o discurso é percebido como efeito de sentido entre interlocutores e compartilhamos a concepção de sujeito como heterogêneo, isto é, "habitado pelo inconsciente e pelo desejo do outro - através de cujo olhar o sujeito constrói sua própria imagem" (CORACINI, 2003, p. 193).

\section{MODOS DE IDENTIFICAÇÃO}

O ato de ouvir, ler e/ou dizer nos transporta à produção de uma imagem do dito e do não dito/dizível. A imagem formada tem um pouco de si e um pouco do outro; os sentidos já ditos por outros, em diferentes contextos ou condições de produção têm um efeito sobre o que o discurso sugere, formando uma imagem não translúcida, considerando que "todo dizer aponta para um outro que o constitui" (CORACINI, 1997, p. 40) e produz efeitos de sentido outros, reveladores de identidade. 


\section{Atos de Pesquisa em Educação - ISSN 1809-0354 \\ Blumenau - vol. 11, n. 2, p.492-508 ago./nov. 2016 \\ DOI: http://dx.doi.org/10.7867/1809-0354.2016v11n2p492-508}

A identidade como construção torna-se pluralizada a partir do momento em que esta se insere como processo, na perspectiva histórica e cultural. As mudanças abalaram as referências e conceitos antigos descentrando o indivíduo, provocando "crise de identidade". As relações passaram a ser provisórias e mais complexas, diante de uma realidade globalizada e variável, onde a fixidez já não se enquadra na fluidez do mundo.

A identidade é desestabilizada no outro e pelo outro, causando estranhamento decorrente da relação de alteridade. Tal instabilidade abala a relação do sujeito consigo mesmo, considerando que na memória está registrada uma determinada universalidade, uma identidade fixa e isso leva o sujeito a não aceitar a inconclusão ou a incompletude (CORACINI, 2003b). Considerando-a como processo, opta-se pelo termo modos de identificação à identidade.

Discutir modos de identificação do(a) professor(a) com a profissão docente implica analisar o dizer desse sujeito para que possamos apreender a imagem através do revelado e do ocultado, o que pode estar nas dobras da língua. É interessante considerar que antes de criarmos a imagem do outro, na condição de sujeitopesquisador(a), ocorre uma antecipação por parte do sujeito-pesquisado em fazer também a imagem do outro-pesquisador. A imagem que identifica o sujeito é formada no e pelo olhar do(s) outro(s). Dessa forma, o(a) professor(a) é o que faz e falam sobre este(a) a partir do papel designado que esteja de acordo com a ideologia. Nesse sentido, Cavallari (2005, p. 10) menciona que "a imagem de si é sempre constituída por intermédio do outro/Outro, seu exterior: é no outro que o sujeito que é falado reencontra o seu eu-ideal, isto é, sua matriz identificatória".

A formação da imagem se dá a partir de "práticas racionais e voluntárias pelas quais os homens não apenas determinam para si mesmo regras de conduta, como também buscam transformar-se, modificar-se em seu ser singular [...]" (FOUCAULT, 1984, p. 198). Trata-se do poder disciplinador que tem como instrumento a disciplina que opera na sujeição do corpo, procurando criar, impor uma relação de docilidade e de utilidade, em uma ação adestradora, uma prática da escola.

Foucault (1979) associa regime de verdade a constrangimento, o que faz sentido, uma vez que o disciplinamento não é aceito passivamente pelos indivíduos, 


\section{Atos de Pesquisa em Educação - ISSN 1809-0354 \\ Blumenau - vol. 11, n. 2, p.492-508 ago./nov. 2016 \\ DOI: http://dx.doi.org/10.7867/1809-0354.2016v11n2p492-508}

mas se dá nos padrões da obrigatoriedade das convenções históricas e culturais da sociedade. Assim, as palavras vão resistindo diante das relações conflituosas operadas nos discursos de acordo as formações discursivas, ganhando interpretações diversas e controversas, tendo a linguagem como elemento de instrumentalização do poder.

\section{MARCAS DE RESISTÊNCIA: UM MODO DE IDENTIFICAÇÃO}

Os discursos são resultantes das relações de poder-saber, processos e lutas, a partir dos quais se constroem o conhecimento, sem se constituir em verdade absoluta. Como sujeito da linguagem e constituído pelo discurso, a identificação - que passa por deslocamentos - é percebida através do discurso construído historicamente na relação sociedade e ideologia. É importante destacar que as condições de produção determinam o que pode e deve ser dito, quem diz, para quem diz, como diz e aonde diz (ORLANDI, 1999). Isso nos leva a procurar significação no não-dito ou no dito de outra forma, além do que está por dizer.

As diferentes formas de dizer/não dizer e o silenciamento podem revelar resistências, observadas em ações e comportamentos uma vez que estas se constituem em formas de expressão de poder (reclamar, controlar, decidir, por exemplos). Trata-se de visões alternativas, cada uma apresentando diferentes possibilidades, embora o poder dominante esteja sempre sujeito à resistência. Segundo Foucault (1979), poder e resistência são faces de uma mesma moeda, o que legitima a resistência como natural do discurso.

Considera-se que o poder circula por diferentes espaços, penetrando em todo lugar, através das relações. Entretanto, o poder não é vitalício em uma relação, uma vez que se movimenta nas relações de lutas e de força. Foucault (1995, p. XIV) afirma que:

Qualquer luta é sempre resistência dentro da própria rede do poder, teia que se alastra por toda a sociedade e a que ninguém pode escapar: ele está sempre presente e se exerce como uma multiplicidade de relações de forças. E como onde há poder há resistência, não existe propriamente o lugar de resistência, mas pontos móveis e transitórios que também se distribuem por toda a estrutura social (FOUCAULT, 1995, p. XIV). 
Atos de Pesquisa em Educação - ISSN 1809-0354

Blumenau - vol. 11, n. 2, p.492-508 ago./nov. 2016

DOI: http://dx.doi.org/10.7867/1809-0354.2016v11n2p492-508

Assim, a escola se constitui em espaço de poder. Um poder que circula nas relações entre gestores e gestores, gestores e professores, gestores e alunos, professores e professores, professores e alunos, alunos e alunos. Poder que também se expressa na relação gestores, professores e alunos com a sociedade e, consequentemente, por meio das políticas educacionais, com suas interpretações e validações.

Destacamos que a cultura escolar gera materialidades a partir de resistências, consensos e embates decorrentes das mais diversas relações sociais, políticas e econômicas. Da mesma forma, tais materialidades também integram à produção da cultura. Assim, ao mesmo tempo em que a escola produz cultura, ela é influenciada pela cultura, sendo tais influências incorporadas à produção cultural como processo que não se esgota.

Assim, os dizeres das professoras revelam modos de identificação com a profissão docente, por via de resistência, bem como de outras formas, a partir dos efeitos de sentido. A partir dos variados efeitos de sentido produzidos pelo professor, em seu "eu" a partir do "outro", são constituídos os diferentes modos de se identificar com a profissão docente. Consideramos que o sentido não é exato (ORLANDI, 2012) e, portanto, o discurso também escapa aos limites da interpretação, possibilita a atribuição de diferentes significados e sentidos às ações e ao universo contextual. Nesta perspectiva, os excertos seguintes foram analisados.

A partir dos variados sentidos produzidos por diferentes membros da comunidade escolar e da comunidade externa a esta, o professor vai traçando diferentes modos de se identificar com a profissão docente. Consideramos que 0 sentido não é exato (ORLANDI, 2012) e, portanto, o discurso também escapa aos limites da interpretação e, como nos indica Hall (1997, p. 16): "os seres humanos são seres interpretativos, instituidores de sentido". Dessa forma, o ser humano atribui diferentes significados ao mundo e às ações.

Optamos por tratar por modos de identificação em supressão do uso do termo identidade. Adotamos os modos de identificação na perspectiva cultural (HALL, 2006), construída pelo inconsciente, ou seja, por um eu a partir do outro (CORACINI, 2003a). 
Atos de Pesquisa em Educação - ISSN 1809-0354

Blumenau - vol. 11, n. 2, p.492-508 ago./nov. 2016

DOI: http://dx.doi.org/10.7867/1809-0354.2016v11n2p492-508

\section{MATERIAL E MÉTODO}

No sentido de atender aos objetivos propostos e com base na Análise do Discurso, optamos pelo instrumento entrevista semiestruturada para levantamento do corpus da investigação. Tal escolha pauta-se em motivos, tais como a possibilidade de se elaborar questões, agrupando segundo a proposta da pesquisa e que mantêm, direta ou indiretamente, alguma ligação ou influência com esta. Por outro lado, destacamos a não neutralidade da pesquisa a partir da influência que o entrevistador exerce sobre o entrevistado (MANZINI, 2003), tanto nos processos de raciocínio quanto nos processos de memória.

A escolha do local da pesquisa não foi aleatória, firmou-se na possibilidade de se obter fácil acesso ao campo e pela possibilidade de contemplar o local de trabalho das pesquisadoras. O corpus é composto por excertos das entrevistas de três professoras que atuam na educação básica, do $5^{\circ}$ ao $9^{\circ}$ ano. As entrevistas foram realizadas no local de trabalho e em residências das professoras, conforme a disponibilidade de tempo destas.

As perguntas foram agrupadas por blocos, envolvendo dados pessoais; o acesso à profissão docente - carreira e permanência; ensino/aprendizagem; articulação com as políticas educacionais; modos de identificação. Outrossim, ressaltamos que em todos os subitens as professoras, através dos seus dizeres, forneceram pistas que nos levaram a identificar diferentes modos de identificação do professor com a profissão docente. Dentre os sujeitos, duas atuavam na função de professora e uma atuava na condição de gestora.

As entrevistas constaram de um roteiro semiestruturado que serviu para manter o foco da pesquisa, embora fosse livre para as professoras a possibilidade de inserção de outros pontos que julgassem importantes. Em média, cada entrevista durou entre 50 a 60 minutos, embora que com uma professora a entrevista durou quase duas horas, por iniciativa deste sujeito de pesquisa. A identificação dos sujeitos foi feita usando-se nomes fictícios: Stela, Rute e Anne. Stela, a gestora e Rute e Anne, todas com mais de dez anos de experiência na profissão docente, são os sujeitos de 


\section{Atos de Pesquisa em Educação - ISSN 1809-0354 \\ Blumenau - vol. 11, n. 2, p.492-508 ago./nov. 2016 \\ DOI: http://dx.doi.org/10.7867/1809-0354.2016v11n2p492-508}

pesquisa. A seguir, apresentaremos alguns excertos $(E)$, resultado e discussão sobre o corpus.

\section{RESULTADO E DISCUSSÃO}

Com relação ao ingresso ou acesso à profissão docente, apresentamos, neste item,os relatos das professoras.

A professora Anne, em E1, relatou:

"Com a conclusão do Magistério em 1996, fui convidada a lecionar numa turma do fundamental I e percebi que estava fazendo algo de que gostava e daí pra cá não faço outra coisa, amo a minha profissão. Estava realizando um sonho de criança e todos ficaram felizes".

A professora Stela, em E2 relatou a questão afirmando: "Comecei em sala de aula, trabalhando com alunos de $5^{\mathrm{a}}$ a $8^{\mathrm{a}}$ série. Comecei a trabalhar com Ciências e depois comecei a ensinar Inglês, permanecendo até assumir a coordenação".Outra entrevistada, afirmou (E3, Rute):

"Acho que ela começou meio assim... Meio que sem escolha, foi por oportunidade... Eu tive oportunidade de fazer Magistério e precisava trabalhar [...] e depois fui fazer Letras para dar continuidade ao curso. Comecei a trabalhar nas séries iniciais, $1^{\circ}$ ano e depois, Fundamental I, ensinei Ciências, Geografia, Artes e depois comecei a trabalhar na disciplina de formação".

Observando os enunciados acima percebemos a presença da pluralidade e como o ser plural é também singular. As professoras deixam resvalar diferentes sentimentos que os ligam à profissão docente, tais como desejo, indiferença e frustração, respectivamente, transitando entre o mesmo e o diferente.

Anne, em E1, demonstra estar se realizando na profissão docente apesar da desvalorização da profissão, nos aspectos social e econômico. Essa postura nos leva a pensar que a afetividade é o ponto alto que produz realização e identificação da professora com a profissão docente. Interessante é que a professora inclui e estende a felicidade ao "outro", ao mencionar "todos ficaram felizes". 


\section{Atos de Pesquisa em Educação - ISSN 1809-0354 \\ Blumenau - vol. 11, n. 2, p.492-508 ago./nov. 2016 \\ DOI: http://dx.doi.org/10.7867/1809-0354.2016v11n2p492-508}

Em E2, Stela não demonstra neutralidade, a princípio, não esboçando sentimento a favor ou contra o seu ingresso à profissão docente.

O dizer de Rute, em E3, coloca a profissão docente na esfera da sobrevivência e demonstra desconforto e o fazer múltiplo dentro da profissão docente, ao mencionar um leque de disciplinas em que trabalhou.

Quando perguntamos aos sujeitos da pesquisa: Quem é o professor, na atualidade? A professora Rute revelou que estes profissionais passam por momentos de angústias e de necessidade de autoafirmação. Passam por desvalorização social, indicando tratar-se de profissionais de uma carreira árdua, conforme pode ser observados nos excertos seguintes (E4, Rute):

"Quem é o professor hoje eu digo que é uma figura desgastada, cansada, doente, estressada. Os desafios dele é vencer tudo isso e entrar na sala e conseguir promover algum aprendizado no aluno que já vem de casa, coitado, sem esperança. [...] Eu acho que a carreira docente do professor, hoje, da rede pública ela é muito árdua, socialmente sem credibilidade [...]”.

Rute caracteriza o professor como "uma figura desgastada, cansada, doente, estressada", fazendo uso da materialidade "eu", conforme pode ser observado em E4. Ao fazer uso do "eu", a professora assume o poder de dizer uma verdade sobre uma classe vitimada no exercício da profissão, fazendo referência à profissão docente, de forma enfática e assumindo o seu dizer. Essa caracterização decorre de uma gama de fatores físicos e sociais, associados a questões políticas, de acordo com o discurso das professoras investigadas. Tais predicativos atribuídos aos(às) professores(as) podem indicar formas de resistência a uma profissão considerada desvalorizada por todos (sociedade), no dizer da professora, mas que continua atuando na profissão, qualquer que seja o motivo.

Esse discurso se constitui em uma maneira de demonstrar insatisfação com a profissão docente, revelando a realidade da classe "sofredora", como é referenciada por algumas pessoas. A sequência do discurso sinaliza para os sentidos e o grau de significação dos problemas elencados. Sinaliza para uma imagem negativa de um grupo suscetível a males físicos e psicológicos, sem grandes perspectivas ou possibilidade de reverter o quadro apresentado pela entrevistada. Nesse sentido, 


\section{Atos de Pesquisa em Educação - ISSN 1809-0354 \\ Blumenau - vol. 11, n. 2, p.492-508 ago./nov. 2016 \\ DOI: http://dx.doi.org/10.7867/1809-0354.2016v11n2p492-508}

Pêcheux (1997, p. 30) assevera que a análise do discurso concebe a linguagem como mediação necessária entre o homem e a realidade natural e social. Essa mediação, que é "o discurso, torna possível tanto a permanência e a continuidade, quanto $o$ deslocamento e a transformação do homem e da realidade em que ele vive".

O discurso, como ideia de percurso e como construção histórica, foi observado em diversos momentos, nos dizeres das professoras. $O$ uso de metáforas é frequente na relação professor(a)/profissão por exemplo. Rute se refere ao professor como "uma figura desgastada", nos fazendo recorrer à Coracini (2002) para classificar a palavra - figura - como um termo metafórico ao considerarmos que: "a metáfora não se resume à palavra, assume seu valor no enunciado, no texto e/ou na situação pragmática do discurso ao qual pertence" (CORACINI, 2002). O termo está associado à imagem da professora sobre o(a) professor(a) e a profissão. $E$ isso deve-se a vários fatores, a partir da desvalorização da profissão docente.

A sobrecarga de trabalho do(a) professo(a) desdobra diferentes efeitos de sentido com relação à profissão docente, por parte do Estado, por alunos e seus pais, e pela sociedade, o que é natural se considerarmos o sentido atrelado a nível pessoal - contextual/histórico. Assim, um sentido pode se deslocar e originar sentidos outros (ORLANDI, 1999).

Ao serem questionadas sobre a profissão docente, as professoras responderam:

"[...] Há essa insatisfação [...]. Esse desmérito, essa descrença no professor porque rico nenhum, jamais deseja pra um filho dele ser um professor. Ele morreria de vergonha, diante de uma sociedade, no grupo dele, dizer que o filho dele é um professor. la dizer que passava fome sentia necessidade ou que não tinha conseguido vaga em outro curso de ponta e tinha se formado em professor".(E5, Rute)

"Embora sendo uma carreira árdua, é gratificante, pois cabe ao professor o papel de agente formador de sujeitos criativos, reflexivos, críticos, competitivos e abertos ao mundo, contribuindo assim em todas as dimensões educativas e formativas".(E6, Anne)

No dizer de Rute percebe-se um grande mal-estar ligado à profissão docente, mais especificamente, em ser professor, principalmente da rede pública. Reflete a 
Atos de Pesquisa em Educação - ISSN 1809-0354

Blumenau - vol. 11, n. 2, p.492-508 ago./nov. 2016

DOI: http://dx.doi.org/10.7867/1809-0354.2016v11n2p492-508

imagem da profissão docente como algo vergonhoso, com profissionais mal remunerados a ponto de associar a profissão à fome e à incompetência. A fala demonstra, também, um sentimento de inferioridade e revela que o professor é vítima de preconceito, ao mencionar "rico", "fome" e "professor".

É interessante que se analise esse dizer, considerando o contexto histórico, social e político em que se insere o sujeito. Percebe-se um distanciamento/ afastamento do sujeito com os considerados ricos, ao usar a expressão "dele". Demonstra, a nosso ver, o atravessamento do outro no seu dizer, há a presença do "outro" e de "tantos outros" interferindo nos modos de identificação com a profissão docente.

A docência não é objeto de desejo e sim algo que a aprisiona e envergonha. Tem-se, nesse caso, a ilusão de que o que move o sujeito seria o desejo, a busca da completude, ou melhor, o sujeito rejeitando a incompletude. Percebe-se, na fenda do discurso, a noção da falta representada pela materialidade "não". Isso se dá ao nível do inconsciente. Mas o sujeito da análise do discurso não é só o do inconsciente; é também, da ideologia, ambos revestidos pela linguagem e nela se materializam. É nesse momento que o sujeito se angustia, é o 'outro' movendo o dizer de Rute, em E5.

Em E6, Anne parece buscar compensação na realização do outro. O seu dizer resvalou na docência como algo missionário. A materialidade "embora" nos leva a fazer a relação de compensação, apontando duas situações adversas entre si.

Quando questionamos sobre o modo como as professoras achavam que os alunos encaravam a profissão docente, as respostas se voltaram para a questão do(a) professor(a), sinalizando que as professoras se constituem dentro da profissão e estabelecem profundo laço profissão/professora. Os dizeres das professoras, Anne, em E7: "Não demonstram aquele respeito que merece e acabam por desrespeitar" $\mathrm{e}$ de Rute, em E8: "Eu acho que é com banalidade, é... Hoje... Não tem uma hierarquia, não tem respeito dentro da sala de aula. Ele vê como mais um dentro da sala de aula, sem diferença", revelam um processo de desqualificação e desvalorização sofrido pelos professores e absorvido pelo aluno, a ponto de ele não reconhecer o(a) 


\section{Atos de Pesquisa em Educação - ISSN 1809-0354 \\ Blumenau - vol. 11, n. 2, p.492-508 ago./nov. 2016 \\ DOI: http://dx.doi.org/10.7867/1809-0354.2016v11n2p492-508}

professor(a) como uma autoridade na sala de aula ou alguém hierarquicamente superior.

O uso da materialidade "hoje" coloca o passado no contexto atual e a nossa memória nos transporta a um passado em que o (a) professor(a) era visto(a) como exemplo, era respeitado, considerado uma autoridade, enquanto hoje professor(a) e aluno(a) hierarquicamente se encontram nivelados, na maioria das situações. $O(a)$ professor(a) convive com a dicotomia da falta e do excesso: a falta de hierarquia, falta de respeito e excesso de indisciplina, e, por outro lado, há o excesso de liberdade do aluno e indiferença e, em alguns casos, até repúdio ou hostilidade. Nesta questão, o professor faz uma interpretação a partir do comportamento do aluno e na sua filiação histórica. Neste sentido, Pêcheux (1990, p. 54) afirma que:

É porque há o outro nas sociedades e na história que pode haver ligação, identificação ou transferência, isto é, existência de uma relação abrindo a possibilidade de interpretar. E é porque há essa ligação que as filiações históricas podem-se organizar em memoriais e as relações sociais em rede de significantes.

Durante os diferentes momentos, o 'outro' esteve constituindo os dizeres das professoras, a partir das filiações de cada sujeito. Culturalmente, ao longo dos tempos, foram construindo e instituindo verdades sobre o(a) professor(a) com relação ao seu papel, ao processo ou percurso e ao produto ou resultados da educação. O discurso do papel missionário do(a) professor(a), por exemplo, propagado ao longo da história da profissão docente serviu como instrumento de manobra e de regulação, além de disciplinamento do(a) professor(a). Trata-se de um discurso consensual - embora não haja consenso total, há exceções - através de marcas discursivas deixadas pelos próprios professores.

Discutir modos de identificação do(a) professor(a) com a profissão docente implica analisar o dizer desse sujeito para que possamos apreender a imagem através do revelado e do ocultado, o que pode estar nas dobras da língua. É interessante considerar que antes de criarmos a imagem do outro, na condição de sujeitopesquisador(a), ocorre uma antecipação por parte do sujeito-pesquisado em fazer também a imagem do outro-pesquisador. A imagem que identifica o sujeito é formada 
Atos de Pesquisa em Educação - ISSN 1809-0354

Blumenau - vol. 11, n. 2, p.492-508 ago./nov. 2016

DOI: http://dx.doi.org/10.7867/1809-0354.2016v11n2p492-508

no e pelo olhar do(s) outro(s). Dessa forma, o(a) professor(a) é o que faz e falam sobre este(a) a partir do papel designado que esteja de acordo com a ideologia. Nesse sentido, Cavallari (2005, p. 10) menciona que "a imagem de si é sempre constituída por intermédio do outro/Outro, seu exterior: é no outro que o sujeito que é falado reencontra o seu eu-ideal, isto é, sua matriz identificatória".

Os discursos resultantes das relações de poder-saber, processos e lutas constroem o conhecimento, sem se constituir em verdade absoluta. Como sujeito da linguagem e constituído pelo discurso, a identificação - que passa por deslocamentos - é percebida através do discurso construído historicamente na relação sociedade e ideologia. É importante destacar que as condições de produção determinam o que pode e deve ser dito, quem diz, para quem diz, como diz e aonde diz (ORLANDI, 1999). Isso nos leva a procurar significação no não-dito ou no dito de outra forma, além do que está por dizer.

As diferentes formas de dizer/não dizer e o silenciamento podem revelar resistências, observadas em ações e comportamentos uma vez que esta se constitui em uma expressão de poder (reclamar, controlar, por exemplo). Trata-se de visões alternativas, cada uma apresentando diferentes possibilidades, embora o poder dominante esteja sempre sujeito à resistência. Segundo Foucault (1979), poder e resistência são faces de uma mesma moeda, o que legitima a resistência como natural do discurso.

Considera-se que o poder circula por diferentes espaços, penetrando em todo lugar, através das relações. Entretanto, o poder não é vitalício em uma relação, uma vez que se movimenta nas relações de lutas e de força. Nesse sentido, Foucault (1995) admite luta como resistência, sendo esta considerada como uma expressão de poder. Trata-se de relações de forças que se deslocam e atravessam o tecido social.

Neste contexto, a escola como lugar de relações de força e de poder entre os membros da sua comunidade. Por outro lado, como espaço de resistência, as relações são exercidas e influenciam novas relações entre os seus pares e sobre as políticas educacionais. É o "eu" envolvendo-se com o "outro" e com "todos os outros", constituindo-se e constituindo. 
Atos de Pesquisa em Educação - ISSN 1809-0354

Blumenau - vol. 11, n. 2, p.492-508 ago./nov. 2016

DOI: http://dx.doi.org/10.7867/1809-0354.2016v11n2p492-508

\section{CONSIDERAÇÕES FINAIS}

Com relação à profissão docente, além do discurso que envolve as políticas públicas existem as subjetivações sobre tal discurso, revelando dizeres contraditórios e importando, antes de tudo, saber sobre as transformações que decorrem dos efeitos de sentido, considerando que os sentidos não são os mesmos para todos, embora, aparentemente, sinalizem para tal. Da mesma forma, as políticas sociais em que estão inseridas as políticas educacionais geram interdiscursos produtores de cultura escolar, construídas nas relações de poder e de saber, atravessada por conflitos e resistências.

A constituição da imagem da profissão docente torna-se algo desafiador. A imagem pública, assim como a imagem pessoal ou a auto-imagem, são formadas pelo atravessamento do outro e pela ideologia à qual se filia. $O$ outro sobre o qual fazemos referência é o outro/eu, o outro(a)/professor, o outro/sociedade e 0 outro/política/Estado. A reputação do professor depende da imagem constituída socialmente. A imagem serve para defender e ilustrar a profissão docente.

A forma como cada sujeito conseguiu significar e produzir sentido em $\mathrm{si}$, a partir do outro e para o outro se constituiu em modos de identificação com a profissão docente, que se constitui no pessoal, de forma transitória e negociável. Os discursos analisados nos reportam ou indicam modos de identificação pelo aspecto da negação e da falta, ou, dizendo de outra forma, a identificação se dá via aspectos não desejados na relação professora e profissão, nos levando a pensar que o que é rejeitado é o que grita, é o que se mostra e é mostrado. As professoras Rute e Stela, essencialmente, se revelaram pela negação e pela falta, demonstrando a ausência de realização pessoal e profissional. Por outro lado, como modo de identificação, a professora Anne se mostra pelo viés da afetividade, concentrando nesse aspecto a sua realização pessoal e profissional.

Neste cenário, o "eu" (subjetivo) é (re)construído pelos vários "outros" da exterioridade, podendo citar, por exemplo, as avaliações institucionais, as políticas de formação de professores e outras políticas de valorização da profissão docente, a imagem que se tem do "outro" sobre o "eu", a relação professor/aluno, além de outros 


\section{Atos de Pesquisa em Educação - ISSN 1809-0354 \\ Blumenau - vol. 11, n. 2, p.492-508 ago./nov. 2016 \\ DOI: http://dx.doi.org/10.7867/1809-0354.2016v11n2p492-508}

constituintes de interdiscursos produtores da cultura escolar e de diferentes modos de identificação do professor com a profissão docente.

Assim, pensamos que a resistência se constitui em uma maneira inversa de dizer sim à profissão docente, no momento que faz uso do poder para protestar e para resistir, dentro da profissão. Importante ressaltar que os modos de identificação são transitórios e por isso, não são estáveis ou fixos, de modo que podem ser alterados de acordo os contextos social, político e histórico.

A constituição da imagem da profissão docente torna-se algo desafiador. A imagem pública, bem como a imagem pessoal é formada pelo atravessamento do outro e pela ideologia à qual se filia. $O$ outro sobre o qual fazemos referência é o outro/eu, o outro(a)/professor(a), o outro/sociedade e o outro/política/Estado. A reputação do(a) professor(a) depende da imagem constituída. Assim, a imagem serve para defender e ilustrar a profissão.

\section{JOSCIENE DE JESUS LIMA}

Doutora em educação pela Universidade São Francisco/SP e doutorado-sanduíche na Universidade de Lisboa, Portugal. Professora titular no Colégio Estadual Dulce Almeida.

\section{MÁRCIA APARECIDA AMADOR MASCIA}

Doutora em Lingüística Aplicada pela Universidade Estadual de Campinas e doutorado sanduíche - University of Wisconsin - Madison. Realizou estágio de Pósdoutorado pela University of Wisconsin-Madison. Professora do Programa de PósGraduação em Educação da Universidade São Francisco/SP.

\section{REFERÊNCIAS}

CAVALLARI, J. S. O discurso avaliador do sujeito-professor na constituição daidentidade do sujeito-aluno. 2005. 220 p. Tese(doutorado) - Instituto de Estudos da Linguagem. Universidade de Campinas, São Paulo.

CORACINI, M.J. Língua estrangeira e língua materna: uma questão de sujeito e identidade. Letras \& Letras, Uberlândia, vol.14, no 1, p.153-169. 1997.

CORACINI, M. J. (Org.). O jogo discursivo na aula de leitura: Língua materna e língua estrangeira. Campinas: Pontes, 2002,141 p. 


\section{Atos de Pesquisa em Educação - ISSN 1809-0354 \\ Blumenau - vol. 11, n. 2, p.492-508 ago./nov. 2016 \\ DOI: http://dx.doi.org/10.7867/1809-0354.2016v11n2p492-508}

CORACINI, M. J. A celebração do outro na constituição da identidade. Revista Organon, vol. 17, n. 35 (pp. 142-156), 2003. Disponível

em:<http://seer.ufrgs.br/organon/article/view/30024>. Acesso em 15 de junho, 2011.

CORACINI, M.J. Subjetividade e Identidade do(a) professor(a) de português. In: CORACINI, M.J. (org.) Identidade e Discurso. Campinas: Editora da UNICAMP, 2003a, p. 239-255.

CORACINI, M. J. O discurso da linguística aplicada e a questão da identidade: entre a modernidade e a pós-modernidade. In: BERTOLD, E. S.; CORACINI, M. J. (Org.). $O$ desejo da teoria e a contingência da prática: discursos sobrelna sala de aula. Campinas, SP: Mercado de Letras, 2003b, 342 p.

FOUCAULT, M.Microfísica do poder(organização e tradução de Roberto Machado). $4^{a}$ ed. Rio de Janeiro: Graal, 1979, 295 p.

FOUCAULT, M.. Sobre a genealogia da ética: uma visão do trabalho em andamento. In: ESCOBAR, C. H. de. (Org.). Michel Foucault: O dossier - últimas entrevistas. Rio de Janeiro: Taurus, 1984. p. 49-50.

FOUCAULT, M.O sujeito e o poder. In: DREYFUS, H. \& RABINOW, P. Michel Foucault. Uma trajetória filosófica: para além do estruturalismo e da hermenêutica. Rio de Janeiro: Forense Universitária, 1995. p. 231-249.

GRIGOLETTO, M. A Resistência das Palavras. Campinas: Ed. da Unicamp, 2002, $236 \mathrm{p}$.

HALL, S. A centralidade da cultura: notas sobre as revoluções culturais do nosso tempo. Educação e Realidade, v. 22, n. 2, p. 15-46, jul/dez, 1997.

HALL, S. A identidade cultural na pós-modernidade. 11 ed. Rio de Janeiro. DP\&A, 2006, $102 \mathrm{p}$.

MANZINI, E. J. Considerações sobre a elaboração de roteiro para entrevista semiestruturada. In: MARQUEZINE: M. C.; ALMEIDA, M. A.; OMOTE; S. (Orgs.)

Colóquios sobre pesquisa em Educação Especial. Londrina: Eduel, 2003. p.11-25.

OLIVEIRA, Dalila Andrade. Os trabalhadores da educação e a construção política da profissão docente no Brasil. Educar em Revista, Curitiba, Brasil, 2010, n. especial 1, p. 17-35.

ORLANDI, E. P. A linguagem e seu funcionamento: as formas do discurso. 4a. ed. Campinas, SP: Pontes, 1996, 277 p. 
Atos de Pesquisa em Educação - ISSN 1809-0354

Blumenau - vol. 11, n. 2, p.492-508 ago./nov. 2016

DOI: http://dx.doi.org/10.7867/1809-0354.2016v11n2p492-508

ORLANDI, E. P. Conhecimento da Linguagem e Filosofias Espontâneas. In: INDURSKY, F. e CRISTINA, M. e FERREIRA, L. (orgs). Os Múltiplos Territórios da Análise do Discurso. Porto Alegre-RS: Editora Sagra Luzzato, 1999, 58 p.

ORLANDI, E. P. Análise de Discurso: princípios e procedimentos. Campinas, SP: Pontes, 2012, $100 \mathrm{p}$.

PÊCHEUX, M. Análise automática do discurso. In: GADET, F.; HACK, T. (Org.). Por uma análise automática do discurso: uma introdução à obra de Michel Pêcheux. 2 ed.. Campinas: Editora da Unicamp, p. 61 a 161, 1990.

PÊCHEUX, M. Semântica e Discurso: Uma critica a afirmação do óbvio. 2: ed.

Campinas, SP. Editora da Unicamp, 1997, 288 p. 